UCRI 90617

\title{
PREPRINT
}

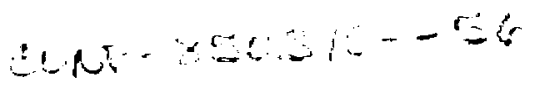

\section{MAGNETIC RIPPLE CORRECTION IN TANDEM \\ MIRRORS BY FERROMAGNETIC INSERTS*}

G. W. Hamilton

This paper was prepared for submittal to the

6th Topical Meeting on the Technology of

Fusion Energy, San Francisco, CA

March 3-7, 1985

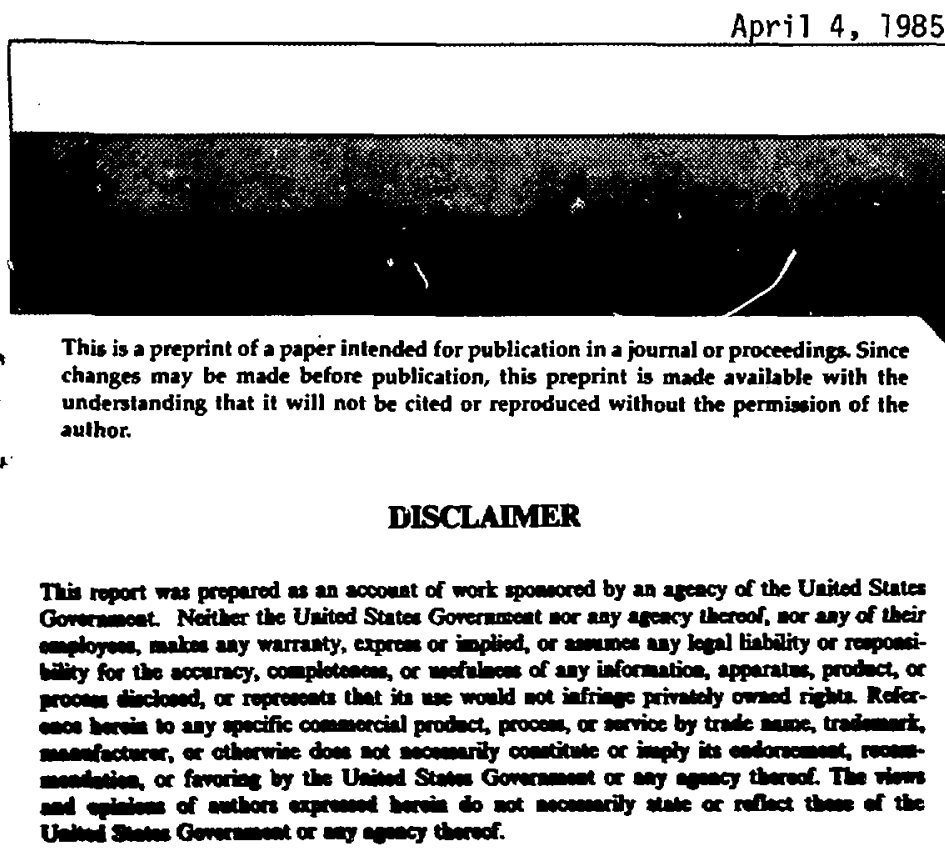

Apri1 4, 7985 
UCRL--90617

DE85 010042

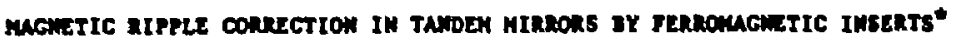

\author{
G. H. HAMILTON, Laurence Liverwore National Laboratory \\ P.0. Box 5511, L-644 \\ Livernore, CA 94550 \\ (415) $422-9800$
}

\section{ABSTRACT}

Magnetic ripple of $1 \%$ or more caused by discrete solenoid coils in the central cells of tander wirrors may severely afiect the MHD stability. The ripple amplitude can be reduced by an order of magnitude by ferromagnetic annuli inserted within the coils at the regions of ripple maxima. The inserts need not affect the accessibility, coil diameter, or capital cost, since large quantities of steel are required within the coils for the neutron blanket and shield. Design of the ripple correction is simplified and linearized by the cylindrical geometry and by the saturation of the ferromagnetic steel.

\section{INTRODUCTION AND SUMMARY}

Magnetic ripple caused by discrete solenoid coils in the central cello of tandem mirrors may severely restrict the plasma beta for KHD stability if the ripple amplitude is much larger than $1 \%$. The ripple problem tends to be more severe as the spacing between solenoid coils is increased for access and as the coil diameter is reduced for economy. Solenoid design must include some type of economical ripple correction compatible with the various requirements of the coils and also of the neutron blanket within the coils.

It was found that at little or no extra expense, the ripple amplitude could be reduced by an order of magnitude through the insertion of ferro-magnetic annuli at the locations of the ripple maxima. In computer testing it was discovered that the induced magnetization of the iron reduced the field at the ripple maxima and increased the field at the ripple minitua. In one example, the ripple amplitude was reduced from 9.57 to 0.57 by iron inserts within the solenoid coils. Ripple correction was designed for several coil geometries, which the paper will describe.
Because in mont fusion reactor designs large quantitie of steel are required within the nagnet ejil for the neutron blanket, reflector, and shield, the iron needed for ripple correction was already available. Thus, to correct the ripple only necesnitated that certain sections of teel blanket, reflector, and shield be specified ferronegnetic, and other sections be specified non-eagnetic.

Ripple correction by ferromagnetic inserts as previously been deaigned for tokamak zactors.1 It appears that the ripple c rrection is easier to achieve in the central c 1 of a tandem mirror, compared to a tokansk, bi ause of the linear geonetry. Also, the compucational design was greatly simplified for the tanden mirror because of the spatially constant indiced magnetization. This constant magnetization was due to the cylindrical geometry and the saturation of the iron. Optimization of coil currents and the iron concent of the inserts was tractable by linear matrix algebra.

The effect of nonuniform blanket temperature on the ripple has been analyzed and found to be very small.

\section{EFFECT OF RIPPLE ON MHD STABILITY}

Computations ${ }^{2}$ in 1983 using the TEBASCO code $^{3}$ indicated that the plasma beta allowable for MHD gtability in the central cells of tandem mirrors can be severely restricted by magnetic ripple due to discrete solenoid coils. In a high-beta plasma this effect is magnified because the ripple percentage in the plasma magnetic field is larger than the ripple percentage in the vacuul wagnetic field. In reactor relevant examples, it was found that the ripple percentage of the vacuut field should be not wore than $1 x$ if this penalty cannot be accepted.

*Work performed under the auspices of the U.S. Department of Energy by the Laurence Livermore National Laboratory under contract rumer :J-7405-EMG-48. 
Thie concluoicm ultimately my te modified becese of more recent conpurations, not yet moliabod, wich inelude the atabijizing effect of the wile. momer, the 1953 results cotivated a exties of colenoid deaigne wich nimimized the magatic ripple wile bein. conetible with anginering requirements of the euparcomductink coils and of the neutron blenket and ohield.

\section{Irens of coleword coIrs}

Two types of oolenoid coile will be considerad in this paper, which I will refer to ac diserete coile and oheet coile, respectively. In eerly versions of tenden mirzor reactors, such a the Mizror Advanced Reactor Study (mas), 4 the solenoid of the central cell was designed an a series of separate coila at intervals of about three meters. Fig. I shows en excmple of such a solenoid, composed of 22 discrete coila. The three-meter spacing was thought to be required to permit accen to the neutron blanket and shield for maintenance, replacesent, and heat transfer. Consequently, the agnetic ripple percentage ( $B_{\max }-$ hin)/R wax was in the range $4 z$ to $10 \%$, repending upon conditions.

\section{FUSION POHER DEMONSTRATOR COMFIGURATION BASTS}

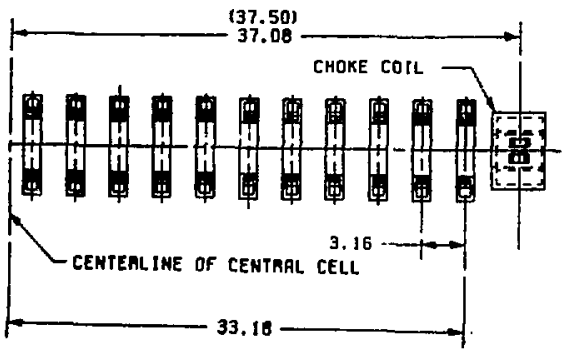

22 CENTAAL CELL COILS

Fig. 1. Coil layout of FPD colenoid Al9, with diecrete coils at intervals of 3.16 meters.

Uning diecrete coils, the ripple percentage can be reduced either by increasing the coil dianter at increased capital cost or by reducing the sracing between coils at the sacrifice of nccessibility. Both of these options are undesirable for the reasona mentioned. A third possibility, to be explained in thio paper, in to correct the ripple with ferronagnetic annuli inserted within the coils.

Recently, under a more aggressive design philosophy, theet coils have been deaigaed in which the conductor bundle consists of continuowe sheet in a module merhape ten enter: loak. Such a nolenoid, how by Fiz. 2, is lighter in wight beceute of the vealler outcide diemter and hisher current denaity. It aloo hoo the advantage of having no eagnetit ripple axeept at the sape betwen odules necasery for access. This design is now being atudied for accesubility and other engineering requiresente.

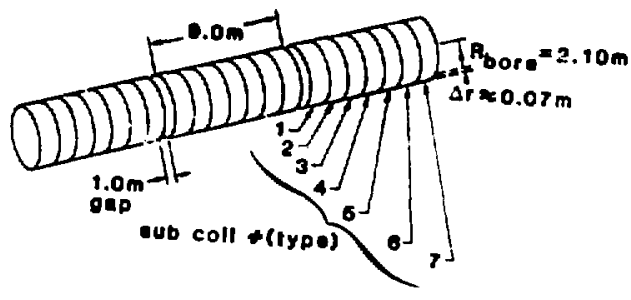

Fig. 2. Coil layout of FPD solenoid A?!, with oheet coils in an assembly 9 meters long with a 1 -meter gap between assemblies. Each assembly consists of 7 sub-asemblies.

\section{MATHEMATICAL MODEL FOR RIPPLE CORRECTION}

Normally the computation of magnetic fields involving ferronagnetic materials require a non-1inear code such a GFUN-3D.5 However. because of simplifications applying to the central cella of tandem mirror reactors a mathematical model has been devied without additional approxinations that can be executed by a linear code wuch as EFFI, 6 which is much easier to set up and to operate than the nonlinear codes. The mathematical simplifications are the following:

\section{Cylindrical symetry.}

2. Saturated iron. Therefore, the magnetization vector $M$ is constant in magnitude and independent of the applied field.

3. $B_{z} \gg B_{F}$. Therefore, the radial component of $M$ can be neglected. $M$ is easentielly conotant in direction as well as magnitude.

4. Hagnetization currents. Since $\underline{M}$ is conotant, there are no masnetisation currents within the iron. At the aurface of the iron, were $n$ in the unit vector normal to the surface, there is aurface angnetization current of the following denoity per unit length :

$$
\underline{J}=(\underline{\underline{n}} \times \underline{y}) / \mu_{0} \quad A / a
$$


Simes 1 is alwye axint and because of cyl indrical symetry, J it aximuthal. The iron insert uill he some kind at annulus with surfece atnetication curtent clockwios on the invide turface and counter-clockvite on the outside urtace. There will be no manetication currents on the end autacea shere $n \times$ I - 0 .

5. Biot-Sayart' Iaw and EFFI. Since ve know the agenetization current, we can replace che iron insert with two concentric coils equivalent to the eurface arnetization currents. The agnetic field $\mathrm{B}(r, z)$ due to these currenta can be computed at any point in spece by BiotSavart"s lay or by the program EFFI. On the axis of symetry. Biot-Savart's Law can be integrated to provide an andytic solution for $\mathrm{B}(\boldsymbol{0}, \mathbf{z})$.

\section{ANALYTTC SOLUTION}

Text books ${ }^{7}$ show that the magnetic field on the axis of a cylindrical solenoid of length $L$ is obtained by integration of Biot-Savart's Law in the range $-L / 2<z<+L / 2$ :

$$
B(0, z)=\mu_{0} J / 2\left(\cos \phi_{1}-\cos \phi_{2}\right)
$$

Here the angles $\phi_{1}$ and $\phi_{2}$ are defined to be subtended at the point $(0, z)$ by the two ends of the cylindrical coil, i.e.,

$$
\tan \phi_{1}=r_{c} / d_{2},
$$

winere $d z_{1}=L / 2-z ; d z_{2}=-L / 2-z$.

In the above, $r_{c}$ is the coil radius (i.e., the radius of the inner or outer surface of the iron annulus) and $\phi_{2}$ is defined similarly using $\mathrm{dz}_{2}$. We use the trigonometric identity $\cos =1 / \sec =1 / \operatorname{sqrt}(1+\tan \hbar \hbar 2)$.

\section{RIPPLE CORRECTION OF A DISCRETE COIL SOLENOID}

As a first example, I used an early version of the Fusion Power Demonstrator (FPD) design, 8 illustrated by Fig. 1, in which the central cell solenoid consisted of 22 discrete coils at intervals of 3.16 meters. EFFI computations showed that the vacuum magnetic field ripple was $9.5 \%$, which was considered not acceptable for high-beta MHD stability.

I assumed that the neutron blanket and shield of the FPD would be essentially the same as the design by the University of Wisconsin for MARS:

Blanket materials: $\mathrm{LiPb}$ neutron absorber HT-9 steel structure

Blanket radii: $59<r<98 \mathrm{~cm}$

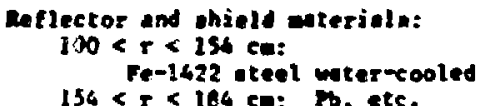

Rippla correction is wont ffective if the ferromanet are as close an possible to the plaan, i.e., juat cutaide the blanket, wich is moity lifb. The reflector and thisld in the region $100<r<154 \mathrm{~cm}$ vere jdeal for cli i. purpose, aince they connisted of $95 \%$ steel. For each coil module 3.16 meters long. I apecified a fercomanetic section 1.75 metero long centered within each coil and a non-antenetic eection 1.41 meter: long between coila.

I sasumed that the exact value of the saturated magnetization $M$ was adjucable by design within limits, ince the ferromagnet. nead not be $100 x$ iron. Using EFFI, 6 I adjusted $M$ to minimize the residual ripple. Fig. 3 shows that the ripple on axis was reduced from 9.56 to 0.457 when I set $M=1.10 \mathrm{~T}$.

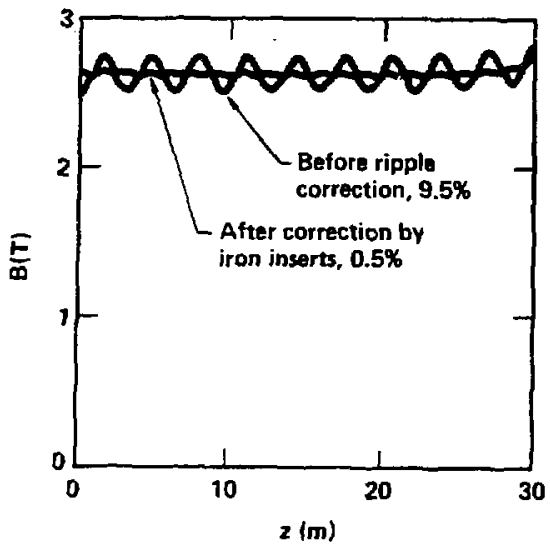

Fig. 3. Graphical EFFI output showing residual ripple, coil set Al9.

Table I shows that the ripple off axis was a!so very small within the volume occupied by the central cell plasma. This is because the plasma radius is small in comparison with the radii of the coils and the ferromagnets.

The residual ripple could be further reduced by adjusting the length $l$ of the ferromagnets or by shaping their surfaces. However, the above results were satisfactory for the purpose of FPD. 
Tanse I

Residual moknetic ripple

* Eunceinn of radiue

within the plater of radiua $45 \mathrm{em}$

$\begin{array}{ccc}\text { R (cm) } & \text { I Ripple } & \text { Dx/Bz, maximum } \\ 0 & 0.452 & 0 . \\ 15 & 0.517 & 0.875 \mathrm{E}-3 \\ 30 & 0.727 & 1.61 \mathrm{E}-3 \\ 45 & 1.167 & 3.094 \mathrm{E}-3\end{array}$

The required magnetization $M=I .10 T$ is consistent with combination of 957 HT-9 sceel $(H>1.15 T)$ and 57 cooling water. These are the fractiona epecified for steel and water in the Mars design.4 The nonmagnetic sections of the reflestor and shield could be Fe-1422, also anecified in the MaRS deaign.

RIPPLE CORRECTION FOR A SHEET-COIL SOLENOID

Each module of the sheet-coil solenoid shown by Fig. 2 consists of seven sub-modules numbered 1 through 7 . The current in each sub-module was adjusted to minimize the ripple, which was 4.47 in version $A 21$, witt one-meter gap 3 between modules for access. In this version the maximum magnezic field, shown by Fig. 4(a), was within sub-modules $l$ and ? because of the extra current used to strengthen the field in the gaps.

I installed iron insezcs 2 meters long at the locations of maximum magnetic field, adjacent to the gap. I then readjusced the currents in each of the seven submodules and readjusted the magnetization $M$ to reduce the ripple to $0.8 \%$ as shown in Fig. 4(b).

\section{RIPPLE CORRECTION BY MATRIX ALGEBRA}

Optimization of coil currents and magnetic iron for ripple corzection can be greatly facilitated by linear matrix algebra. The magnetic field $\underline{B}(r, z)$ is a linear function of coil currents and magnetization currents and is a nonlinear function of the dimensions of the coils and of the magnetic iron inserta. Ripple correction requires optimization of about 10 independent variables, which can be laborious by crial-and-error.

However, trial-and-error is not necessary to optimize the independent variables of which $B(r, z)$ is a linear function. This part of the optimization can be done precisely by matrix algebra. Therefore, the optimization is most easily done by using iterative guess-work to choose the dimensions and by using matrix inversion to determine the currents after each choice of dimensions.

\section{EXAHPLE}

As en example, I will use Dulner's FPD sheet-coil assembly A2! thown by Fig. 3, which conniot: of eix colenoids 9 meters long with sapu of 1 meter between molezoide. To reduce the ripple to 4.42 , each solenoid consises of 7 eccejons each of wich is adjusteble in current density.
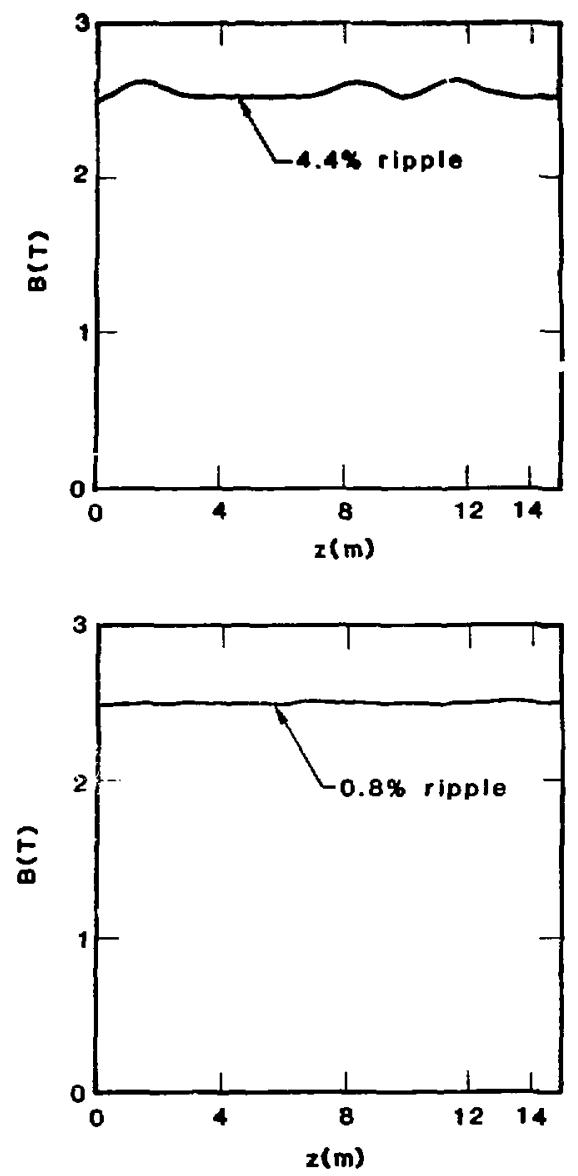

Fig. 4. Graphical EFFI output showing residusl ripple, coil sets $A 21$ and $A 21 G$.

(a) No iron. $4.4 \pi$ ripple.

(b) With iron inserts and with re-optimized coil currents. 0.87 ripple.

In version A21G I add iron inserts adjacent to the gap and readjust tine seven coil currents and four surface manetization currents to reduce the residual ripple to $0.8 \%$. By symetry the seven coil currents are specified by four unknown currents. The four agnetization 
eurrente are equal in dennity but in opposite directione, and are opecified by one edditional unknown.

\section{MatRIX OrERATIONS}

The oheet coil conductors are onty $7-\mathrm{cm}$ thick and san be replaced with a urface current of zero thicknese. For coil current $J(i)$ Aaperes/linear meter, the magnetic field on the axis of symetry at point $j$ it

$$
B(j)=a(i, j) g(i)
$$

where the coefficient $\triangle(i, j)$ is known enalytically by equations (2) and ( 3 ).

We have a totel of at least 66 unknown furrents in the FPD solenoid, which consists of 6 or more assemblies, each involving 7 coil currents and 4 magnetizetion currents. By symetry, these can be combined into four unknown coil currents and one unknown magnetization current. Equation (4) can be considered to be the sum of five terms, where the summa$t i o n$ is indicated by the repeated index $i$.

If we specify $B(j)=2.5$ Tesla at five different locations $z(j)$, equation (4) becomes a system of five simultaneous equations with the five unknowns $\mathrm{J}(\mathrm{i})$. In matrix notation, the five equations are:

$$
\underline{B}=\mathbf{A} \underline{J}
$$

where $B$ and $J$ are 5-dimensional vectors and $A$ is a $5 \times 5$ matrix with matrix elements $a(i, j)$. The solution is

$$
\underline{J}=A^{-1} \underline{B}
$$

where $A^{-1}$ is the inverse of matrix $A$.

PROGRAM MAT4

To carry out this computation, I wrote a Fortran program MAr4 which carries out the folluwing operations:

1. Subroutine Cosine computes the matrix elements $a(i, j)$ by equations (2) and (3) for each of the 66 currents in the FPD solenoid at each of the five points $z(j)$. These contributions by coils with equal currents are added appropriately by MAT4 to compile the $5 \times 5$ matrix A.

2. The IMSL Subroutine LGINF inverts the matrix $A$ to produce $A^{-1}$. Then MAT4 computes the five-dimensional $J$ vector by the matrix multiplication of equation (6).

3. The linear current densiries $J(i)$ are converted to area current densities $\mathrm{j}(i)$ by dividing by the coil thickness ( $7 \mathrm{ca}$ ).
4. Finally, to verify the correctane of the ectix inveraion, Mrth verifies by etrix cultiplication that

$$
A A^{-1} \cdot 1 \text {, the unit watix }
$$

The output $j(i)$ of MaTh it fed into EFr to compute the angetic field $B(r, z)$. The computer work is guaranteed to be correct if the EFTI output whow $B(j)=2.50$ Tesle at the five secified pointa.

\section{RESULTS}

Fig. 4(a) show the sraphical EFrI outpul thowing the 4.47 ripple of coil set $A 21$, which had been manually optimized without iron. For couparison Fig. $4(\mathrm{~b})$ shows the $0.8 \mathrm{x}$ reaidual ripple of $A 21 G$, corrected by iron insert and re-optimized by matrix algebra. The re-optimization is indicated by Table 1 .

\section{TABLE II}

Optimized Coil Currents and Dimensions
PERCENT RIPPLE

$$
\text { j }(A / m 2)
$$

COIL DTMENSIONS

$$
\begin{aligned}
& \text { radius (m) } \\
& \text { length of assembly (m) } \\
& \text { thickness (m) } \\
& \text { gap between assemblies } \\
& \text { number of assemblies } \\
& \text { coils each assembly } \\
& \text { length of each coil }
\end{aligned}
$$

IRON INSERTS in A2lG

$$
\begin{aligned}
& \text { position } \\
& \text { length (m) } \\
& \text { inside radius (m) } \\
& \text { outside radius (m) } \\
& \text { surface magnetization } \\
& \text { currents J (A/m) } \\
& \text { average magnetization } \\
& \text { (Tesla) = } \mu_{0} \mathrm{~J} \\
& \text { saturation strength } \\
& \text { of HT-9 (Tesla) } \\
& \text { required percentage } \\
& \text { of HT-9 in insert }
\end{aligned}
$$

$\begin{array}{cc}\text { A21 } & \text { A21G } \\ \text { no iron } & \text { with iron } \\ 4.47 & 0.87\end{array}$

$\begin{array}{ll}4.697 E 7 & 4.503 E 7 \\ 2.145 E 7 & 2.481 E 7 \\ 3.053 E 7 & 2.561 E 7 \\ 2.693 E 7 & 3.052 E 7\end{array}$

$2.693 E 7 \quad 3.052 E 7$

$\begin{array}{ll}2.1 & 2.1 \\ 9 . & 9 . \\ .07 & .07 \\ 1 . & 1 . \\ 6 . & 6 . \\ 7 . & 7 . \\ 9 / 7 & 9 / 7\end{array}$

EFFECT OF NON-UNIFORM TEMPERATURE OF FERROMAGNETIC IHSERTS

In some reactor designs the tenperature of the neutron reflector and shield is not uniform. Therefore, the magnetization $M$ of the saturated iron is non-uniform and there will be 


\section{armetitation curzente within the iron a wall} a on the custacet.

r.ing sowe of the cechniquea of attaya, 9 I have modeled this aituation, including maknetiz:cion currenta within the iron, asumink tesperaturea in the range from $330-500^{\circ} \mathrm{C}$, as in the Mars design. As thown in Table III, the cemprature difference have a very small effect on the magnetic ripple under these conditions:

TABLE III

Effect of azimuthal temperature gradients upon magnetic ripple correction

$y$-coordinate

Residual Ripple

+0.3 m (near the cooler iron)

$1.10 \%$

0. (on axis)

$0.79 \%$

$-0.3 \mathrm{~m}$ (near the warmer iron)

$0.89 \%$

\section{ACKNOWLEDGENTS}

Valuable advice was provided by Prof. Glenn Bateman of Georgis Institute of Technology and by Dr. Hosny Attaya of University of Wisconsin.

\section{REFERENCES}

1. G. BATEMAN and J. R. FOX, "Smaller Coi? Systems for Tokamak Resctors," Proceedings of the 10th Symposium on Fusion Engineering, Philadelphia, 1983, pp. 812-815 IEEE, New York (1983).

2. R. H. BuLMER, "Center-Cell Ripple Ef rects on MHD Performance," Lawrence Livermore National Laboratory, Fusion Power Demonstration Memo 84-019 (1983).

3. L. D. PEARLSTEIN, T. B. RAISER, L. L. LODESTRO, N. MARON, W. M. NEVINS, P. A. WILLMANN, "TEBASCO User's Guide," LLNT.

4. B. G. LOGAN et al., "MARS, Mirror Advanced Reactor Study, Final Report, "UCRL-53480, Laurence Livermore National Laboratory (1984).

5. A. G. A. M. ARMSTRONG, C. J. COLliE, N. J. DISERENS, M. J. NEWMAN, J. SIMKIN, C. $W$. TRONBR IDGE, "GFUN-3D User Guide," RL-76-029/A, Rutherford Laboratory Report (1976).

6. S. J. SACKETT, "EFFI - A Code for Calculating the Electromagnetic Field, Force, and Iriductance in Coil Systems of Arbitrary Geometry," UCID-17621, Lawrence Livermore National Laboratory (1977).

7. For example: B. I. BLEANEY and B. BLEANEY, Electricity and Magnetism, pp. 132-133, Oxford Ũniversity Press (1957).

8. c. D. HENNING et al., "Pusion Power Demonstration: Baseline Report," UCID-19975, Laurence Livermore National Iaboratory (1984). The final report vill be iasued as 1 UCRL in 1985 .
9. H. ATTAYA and 6. 1. KULCINSKT, "Effect of Tenperature on Magnetic Field Perturbacions from the Ferronagnet ic Blanket in MARS," Proceedings of the Fifth ANS Topical Meeting on the Technology of Fusion Enerky, Knoxville, TN (1983).

10. G. H. HAMILTON, "Temperature Effecto on Iron Inserta for Ripple Correction," LLNL-FPD-84-44 (1984). 